Classification

Physics Abstracts

61.30

\title{
Induction of chirality in nematic phases $\left(^{*}\right)$
}

\author{
G. Chilaya $(* *)$ \\ Laboratoire de Physique des Solides, Université de Paris-Sud, Bt. 510, 91405 Orsay, France \\ (Reçu le 13 novembre 1980, révisé le 2 février 1981, accepté le 6 février 1981)
}

\begin{abstract}
Résumé. - Des dispositifs de visualisation ou d'affichage à cristaux liquides utilisent les propriétés électrooptiques ou thermotropiques particulières à la phase cholestérique quand le pas de son hélice est de l'ordre de la longueur d'onde de la lumière et quelques micromètres.

Les composés les plus connus présentant naturellement cette phase avec des pas appropriés sont les esters de cholestérol ; malheureusement ces corps ne sont pas très stables chimiquement. Des nématiques stables tordus, soit par mélange avec un composé chiral, soit par adjonction d'un radical chiral permettent aussi de réaliser cette phase. Dans ce cas le pas dépend d'un grand nombre de facteurs. Cet article rassemble les prédictions théoriques sur l'influence des concentrations, de la température ou du radical adjoint sur le pas et les confronte à un ensemble très complet de résultats expérimentaux originaux ou déjà connus.
\end{abstract}

\begin{abstract}
Some electrooptic and thermooptic effects of cholesteric phase are used in liquid crystal visualisation and display systems provided spiral pitch is equal to a visible wavelength or several micrometers. Liquid crystals with cholesteric properties were generally cholesteric esters. Unfortunately these materials are chemically nonstable. More stable nematic liquid crystals twisted by mixing with chiral materials or by adding assimetric side chain have also cholesteric phase. In this case spiral pitch depends on many factors. This report unites theoretically predicted temperature and concentration dependence of pitch and compares it with some original or known results.
\end{abstract}

Introduction. - Cholesteric liquid crystals (CLC) have been known for a long time. The first liquid crystal, synthesized by Reinitzer in 1889, was cholesteryl benzoate $[1,2]$. It has also been known that nematogenic systems have cholesteric structure, if their chain contains the assymetric centre. This fact was observed by Friedel in 1922. It is known as well, that mixtures of nematic and cholesteric liquid crystals can exhibit cholesteric structure.

The interest in application of cholesteric liquid crystals in visualisation and display systems has been grown recently. On the whole CLC is used in thermography. Lately two electro-optical effects in CLC were discovered : Dynamic scattering with storage mode and cholesteric nematic phase transition. These effects are described in books $[3,4,5]$. Mainly derivatives of the cholesterol such as cholesteryl esters are used in techniques. However, cholesteryl esters appeared nonstable chemically and electrochemically, while nematic liquid crystals (NLC) are applied successfully.

$\left(^{*}\right)$ A shortened Russian version of this review is to be published in Trudi Inst. Kibernetiki Acad. Nauk. GSSR, Tbilisi, USSR, 1980. (**) Permanent Address : Institute of Cybernetics Academy of Sciences of Georgian SSR, 380086, Tbilisi, S. Euli str. 5, USSR.
Accordingly the question of induction chirality in nematogenic systems arose. The chirality can be achieved by nematic-like compounds with an assymetric side chain (named chiral nematics) or by preparing mixtures of a NLC and an optically active compound (mesogenic or nonmesogenic).

The problem of cholesteric pitch and its temperature and concentration dependence is the central problem of these cholesteric systems. Up to now no general theory concerning the problem has been presented.

In recent years some theoretical and experimental research on the subject was performed in the Soviet Union. A certain ideology has been established which in our opinion is a step towards the solution of the problem.

We would like to propose a review paper in which we would try to outline the world's main achievements in this field paying a special attention to the results obtained in the Soviet Union recently.

The first three chapters are devoted to helical twisting power of optically active dopants (OAD), the temperature and concentration dependence of nematic-chiral mixtures. And the last fourth chapter describes chiral nematics. 
1. Helical twisting power (HTP). - It is known that in nematic chiral mixtures for small concentration $(C)$ of optically active dopant (OAD) the linear dependence of inverse pitch $1 / P$ versus $C$ is observed : $1 / P=A C . A$ is the helical twisting power (HTP). If $C$ is the molar concentration, we will write $A_{\mathrm{M}}$. If $C$ is the weight concentration, then we shall denote it by $A_{\mathrm{w}}$. When instead of $C$ we take mole or weight fraction, we have $\beta_{\mathrm{M}}=A_{\mathrm{M}} / 100$ and $\beta_{\mathrm{W}}=A_{\mathrm{W}} / 100$.

Let us consider at first the case when OAD is nonmesomorphic.

Chistiakov [6] studied the structure of mixture p-azoxyanizole with rosin. Drops observed in polarizing microscope had a cholesteric structure.

Buckingham, Ceasar, Dunn [7] investigated the mixture of p-n-octyloxybenzoic acid with d-tartaric acid. Measurements of the scattering of laser beam by the solution placed in a magnetic field show that addition of small optically active solute molecules to NLC change it to cholesteric mesophase.

Stegemeyer [8-12] determined the influence of the structure of the chiral guest molecules on the HTP. In the table I values of $A$ of the paper [8] are listed. Comparing $A$ values for d-amylalcohol, d-amylace- tate, d-octanol, d-amylester benzoic acid, it can be seen that with extension of chain the values of $A$ increase. According to Park and Labes [13]. The large value of $A$ for phenyl etylamine (PEA) is the result of substitute reaction of amynogroup. The highest $A=0.32$ has inherently dissymetric 6,7-diphenyl, 5,8-diaza-dinaphtho-2'1', 1.2, 1'2", 3.4) cyclooctatetraene (DDCO).

Berthault, Billard, Jacques [14] measured HTP of homologous series of 2-naphtoxy- $\alpha$ substituted acetic acid by $\mathrm{C}_{n} \mathrm{H}_{2 n+1}$ radicals in tolans (Table II).

If OAD interacts with NLC, then $A$ is increased as well as $\alpha_{D}$ (optical rotation of the chiral molecule). In the thesis of Berthault [15] together with substances listing in table II, izoborneol and camphorae are used as $\mathrm{OAD}_{\mathrm{s}}$. They have a small value of

$$
A \sim 0.003 \div 0.001 \text {. }
$$

Ruxer, Solladie, Candau :[16] showed that chiral ketone and series of chiral substituted dibenzo diazocines have a high HTP in p-methoxybenzylidene- $p^{\prime}$ n-buthylaniline (MBBA) (Table III). Table III shows a marked difference in $A$ values according to the aldehide location : HTP is about twice more when the

Table I

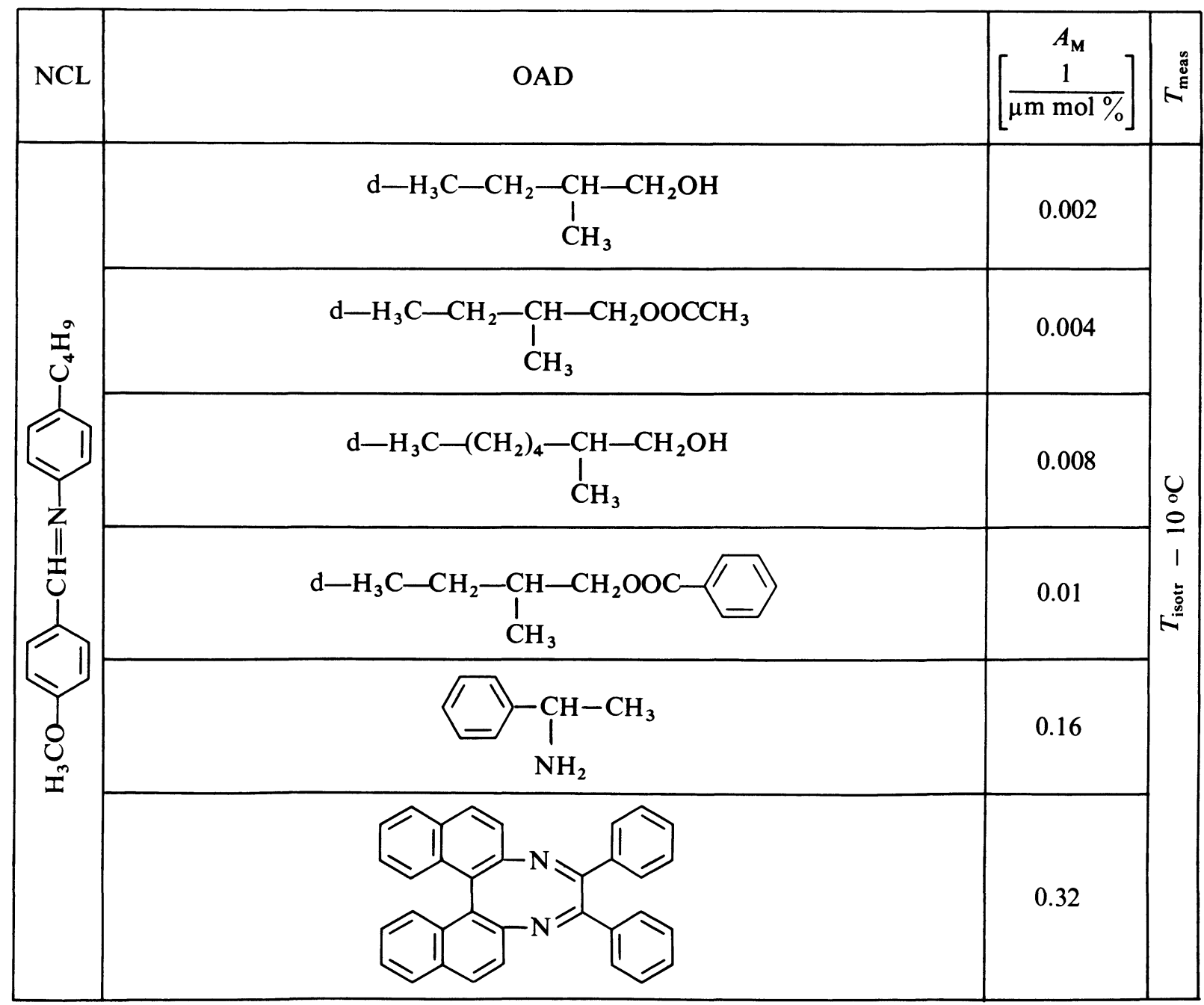


Table II

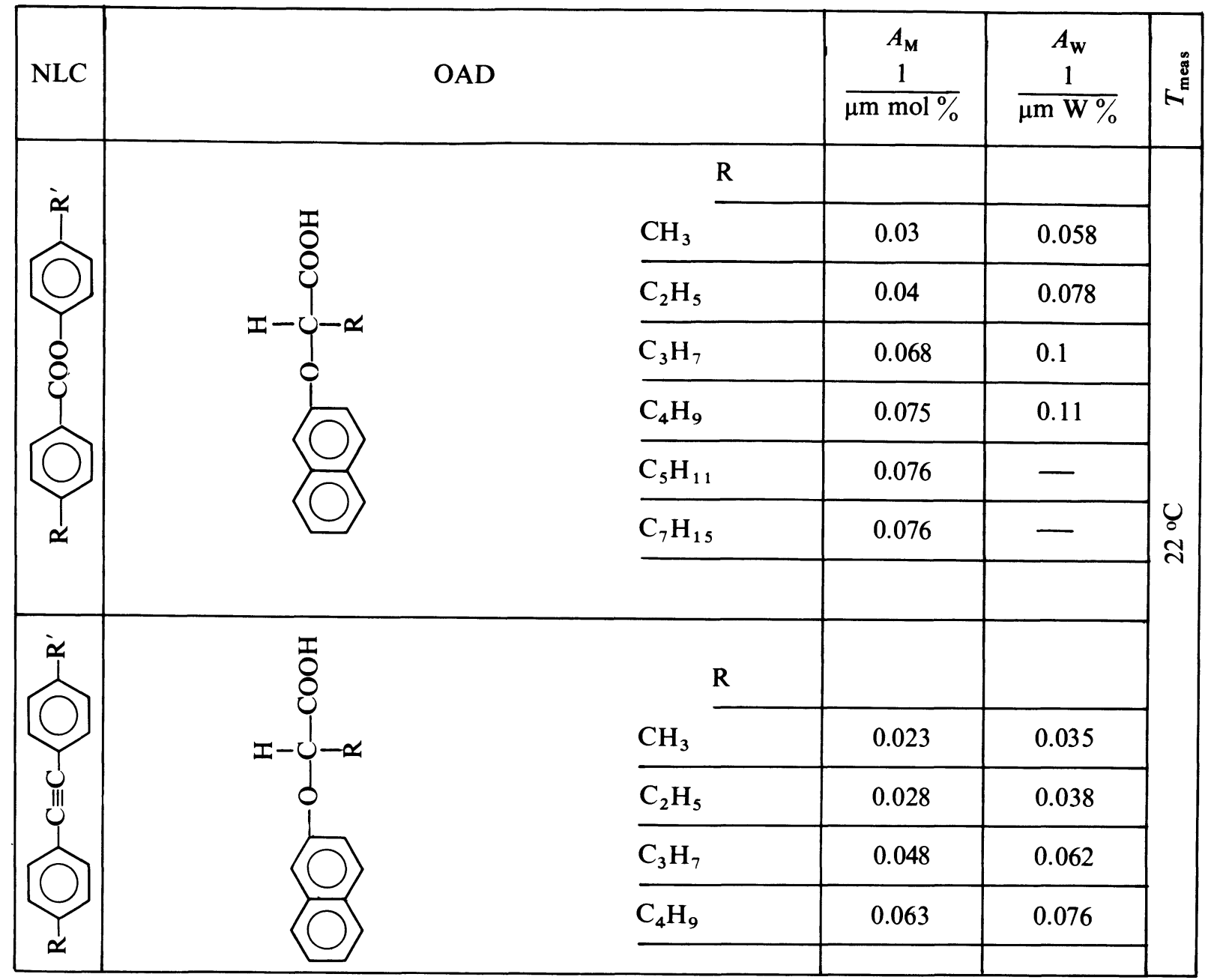

aldehide is in ring $\mathrm{C}$. The value of $A$ is independent of $\alpha_{\mathrm{D}}$.

In $[17,18]$ derivatives of L-menthol, tygogenyn, tygogenynacetate are used as $\mathrm{OAD}_{\mathrm{s}}($ Table IV). These works show the important role of stereochemistry. The addition of coplanar fragments to L-menthol increases $A$. In [19] it has been shown that at low concentration of $\mathrm{OAD}_{\mathrm{s}}$ the viscosity of mixtures correlates with $A$, whereas the specific geometry of the molecules has remarkable influence on higher concentrations.

Let us consider HTP for cholesterol esters and chiral nematics $(\mathrm{CN})$. Usually $A$ depends on the intrinsic pitch $P$ for $\mathrm{CN}$, as the linear dependence $1 / P$ on $C$ is observed and $A=\frac{1}{P .100}$. In the table $\mathrm{V}$ data obtained by Heppke and Oestraicher [20] for $\mathrm{CN}$ are given. A large value for $A$ is reported for $P$ methoxybenzyliden- $P^{\prime}$ aminocinnamate active octyl ester (MBAC) $A=0.19$.

For cholesterol esters $A$ may be greater than the slope of straight line connecting points with $C=0$ and $C=100 \%$.

HTP for CLC varies from 0.05 to 0.1. For example in p-buthyl-P'-methoxyazoxybenzene (BMAOB,
Merck IV) cholesteryl nonanoate has $A=0.084$, cholesteryl chloride 0.053 , cholesteryl miristate 0.087 [20], cholesteryl caprinate $0.07[20,21]$.

2. Concentration dependence of the pitch in nematic chiral mixtures (NCM). - In $\S 1$ we considered NCM for a small concentration of OAD. Now we consider a case for $C$ in all the range from 0 to $100 \%$.

The first investigations of the pitch dependence on concentration in nematic-cholesteric mixtures were reported by Saeva and Wysocki [22] and Nakagiri, Kodama, Kobayashi [23]. Later a number of theoretical and experimental works considering this question appeared. For the dependence of reciprocal pitch $(1 / P)$ versus concentration of optically active dopant four different cases are observed (Fig. 1).

Let's consider the case 1 figure 1 . In this case linear dependence $1 / P$ on $C$ is observed. This case is possible when the molecules of NLC and CLC are chemically similar (or almost similar), they differ from each other only by the presence of an optically active center in CLC. The mixture of the chiral nematic (CN) and its racemic form (NLC) may give an example of this situation [24-25], though it is more correct to consider the racemic form as a mixture of right and left handed 
Table III

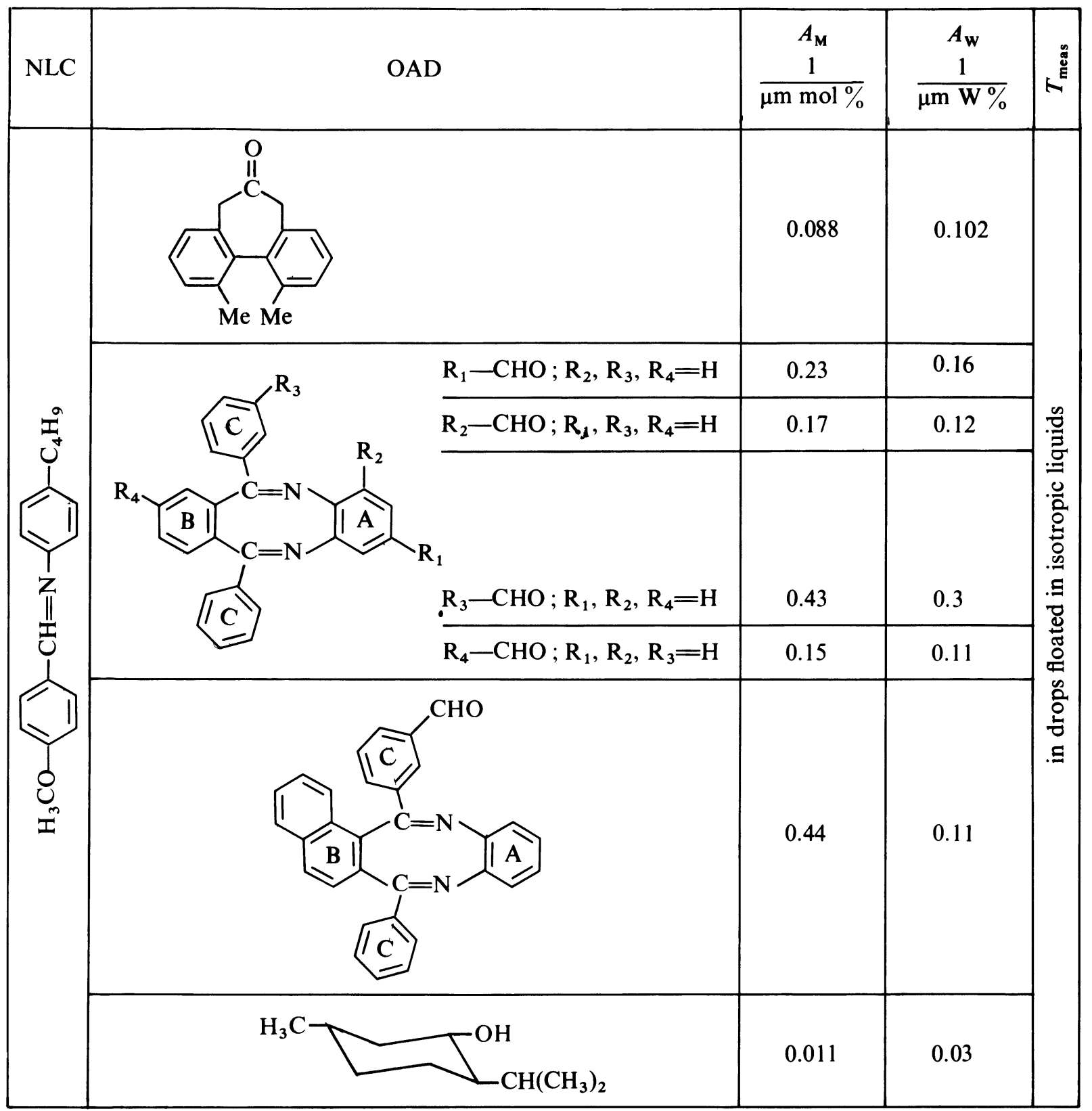

components. In this case $\boldsymbol{P}=\infty$ corresponds to $C=50 \%$ (dashed curve). A linear behaviour was observed also in mixtures of nematic MBBA and cholesteric cholesteryl-2-propyl-1-yl carbonate (CPC), even though these two components are chemically dissimilar [26]. Case 2 is often observed for mixtures of NLC with left-handed cholesteric esters [27, 28]. However, sometimes a plot without extremum was observed in such mixtures as, for example, BBBA and cholesteryl oleat (CO) [26] (case 3).

Case 4 is observed for mixtures of NLC with righthanded cholesterics [22, 29-31].

Now we consider several theoretical approaches used to explain qualitatively the concentration dependence of the pitch in binary systems.

Adams and Haas [32] carried out a phenomeno- logical consideration for the dependence of pitch versus composition in binary liquid crystal systems. For the Helical Twisting Power (HTP) $-1 / P$ - of two component system (the components 1 and 2) they wrote the empirical linear law :

$$
\frac{1}{P}=W \cdot \frac{1}{P_{1}}+(1+W) \cdot \frac{1}{P_{2}}
$$

where $W$ is weight fraction of ingredient $1,1 / P_{1}$, $1 / P_{2}-$ HTP of 1 and 2. (In the paper [32] authors used specific rotation $\frac{1}{\lambda_{\mathrm{m}}}=\frac{1}{2 n P_{0}}$ where $n-$ is average index of refraction, $P_{0}$ - half of pitch, $\lambda_{\mathrm{m}}$ - the wavelength of maximum selective reflection. We decided to write the equation in general form.) 
Table IV

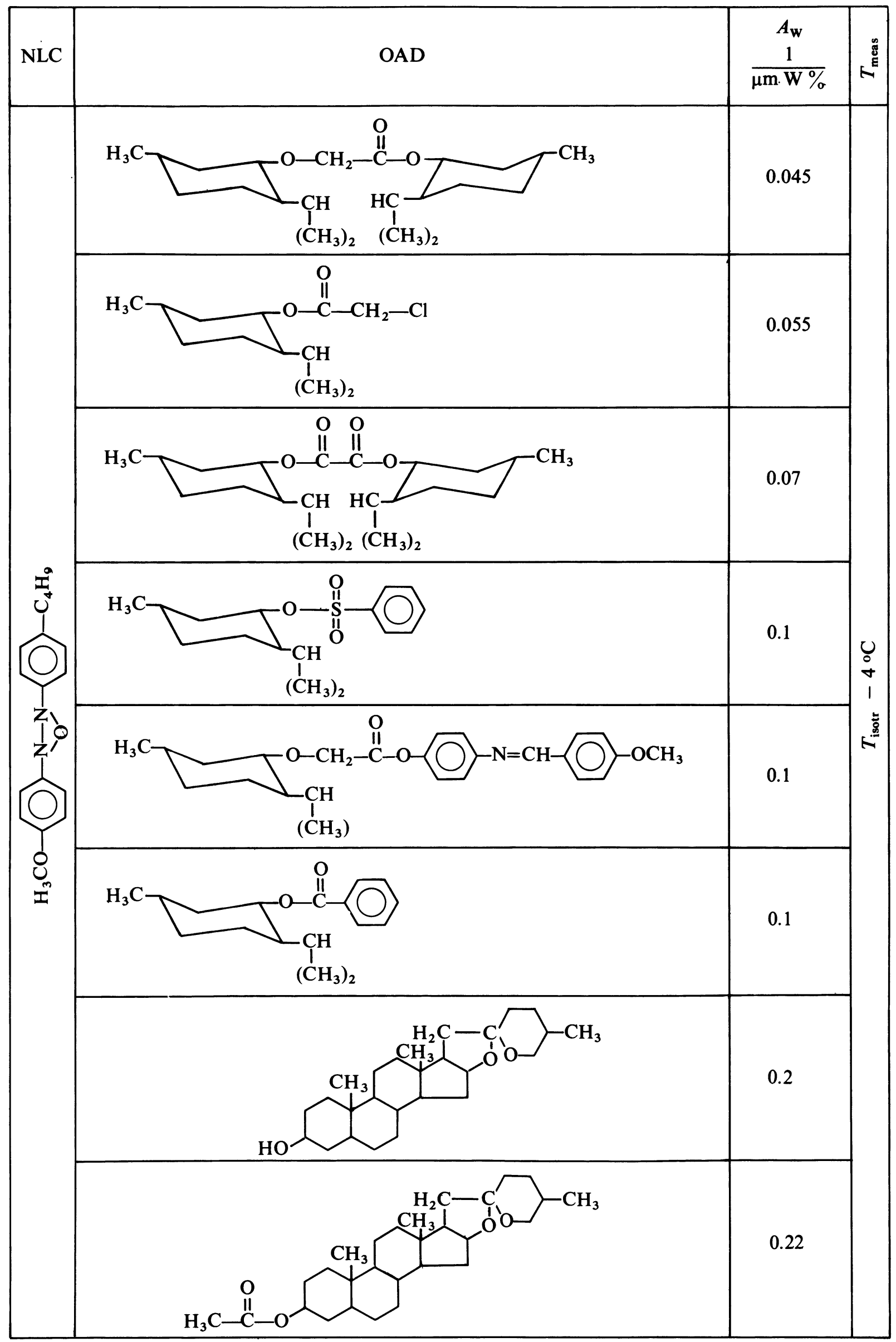


Table V

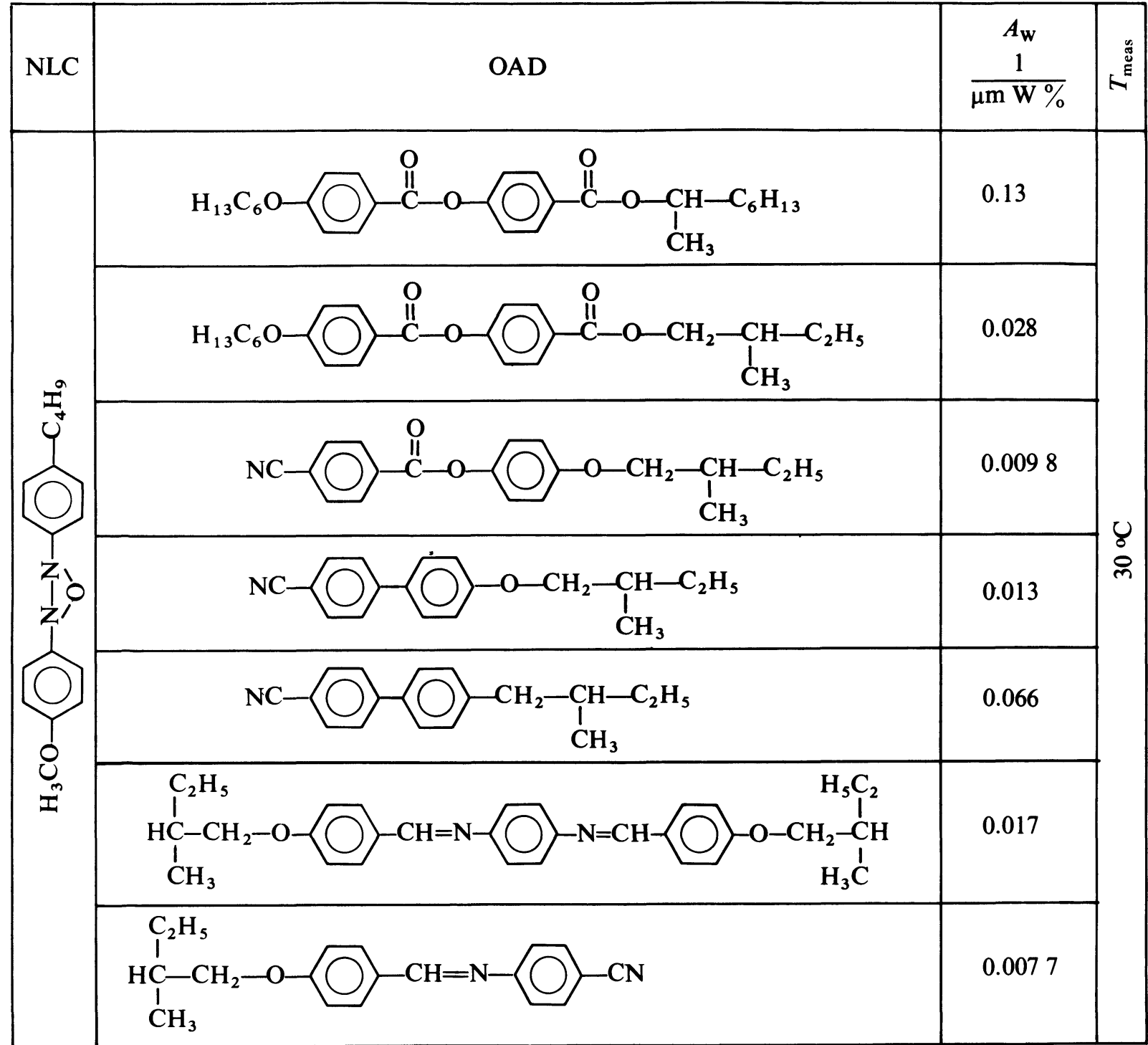

1

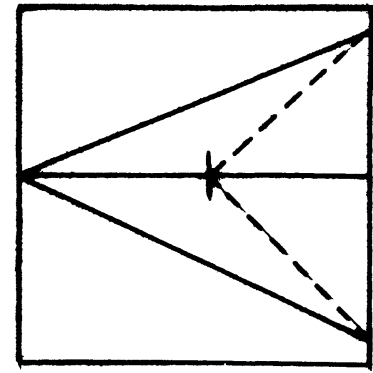

2

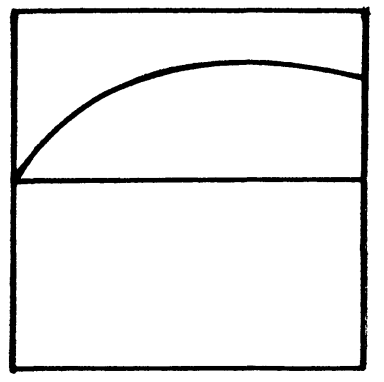

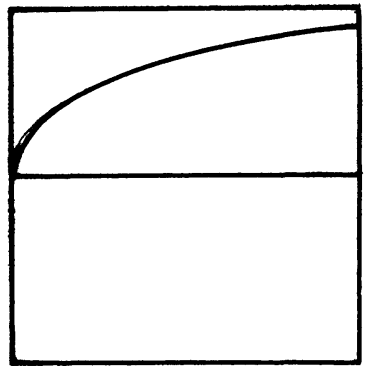

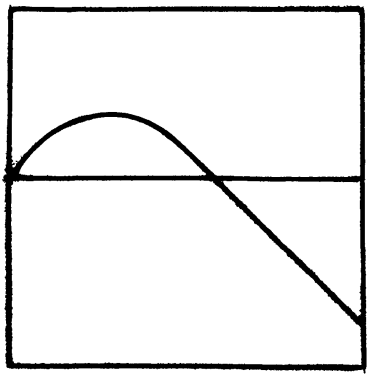

4

Fig. 1. - Four cases observed for the dependence of the reciprocal pitch (vertical axes) and concentration of optically active dopant (horizontal axes) [32]. 
Further the authors took into account the influence of the presence of 1 and 2 and conversely. $K_{1}^{2}$ is modification of HTP for 1 due to the presence of 2. Similarly $K_{2}^{1}$ is introduced. Then (1) becomes quadratic in $W$

$$
\begin{aligned}
\frac{1}{P}=W\left[\frac{1}{P_{1}}+(1-\right. & \left.W) K_{1}^{2}\right]+ \\
& +(1-W)\left[\frac{1}{P_{2}}+W K_{2}^{1}\right] .
\end{aligned}
$$

Since it is impossible to distinguish isolate $K_{1}^{2}$ and $K_{2}^{1}$ values experimentally (2) can be written as

$\frac{1}{P}=W \frac{1}{P_{1}}+(1-W) \frac{1}{P_{2}}+W(1-W) K(1,2)$.

By Adams and Haas [32] the case 1 in figure 1 corresponds to $K(1,2) \cong 0$ case 2 and $3-K(1,2)>0$ and case $4 K(1,2)<0$.

For $N$-component system we have

$$
\begin{array}{r}
\frac{1}{P}=\sum_{i=1}^{N}\left[W_{i} \frac{1}{P_{i}}+\sum_{j=i+1}^{N} W_{i} W_{j} K(i, j)\right], \\
\qquad \sum_{i=1}^{N} W_{i}=1 .
\end{array}
$$

Mathematical calculations were made by Stegemeyer and Finkelman [8]. The theory of Goossens [33] for CLC was extended by them to describe a composition dependence for binary systems. According to
Goossens theory, in order to explain the helical structure one needs to take into account not only the dipole-dipole interaction, as it was done in theory of Maier and Saupe, but also the dipole-quadrupole interaction. The dispersion interaction energy $V_{i j}$ is written as

$$
V_{i j}=V_{i j}^{p p}+V_{i j}^{\mathrm{pq}}+V_{i j}^{\mathrm{qp}}
$$

where $V_{i j}^{p p}$ is perturbation energy of dipole-dipole interaction, $V_{i j}^{\mathrm{pq}}$ - perturbation energy of combination dipole-dipole and dipole-quadrupole interaction. The interaction energy between molecule $i$ in a quasinematic plane a and molecule $j$ in the neighbouring quasinematic plane $\underline{b}$ averaged over all positions, is represented by

$$
V_{\mathrm{ab}}=-\frac{3}{16} \frac{1}{r^{4}}\left(A \cos 2 \theta+\frac{2 B}{r} \sin 2 \theta\right)
$$

where $\theta$ is the angle between the planes a and $\underline{b}, r$ is the separation between them. Coefficient $A$ is determined by the anisotropic part of the polarizabilities of molecules and $B$ by the dipole-dipole and dipolequadrupole interaction between molecules.

Stegemeyer and Finkelmann used Goossens theory for mixtures. Let us consider the case where the nematic monolayer of cholesteric lays in plane $X Z$ and cholesteric helix axis is oriented along $Y$ axis.

Minimizing $V_{\text {ab }}$ with respect to the twist angle $\theta$ one obtains

$$
\theta=\frac{1}{r} \frac{\left(B_{11}-B_{12}-B_{21}+B_{22}\right) W_{1}^{2}+\left(B_{12}+B_{21}+2 B_{22}\right) W_{1}+B_{22}}{\left(A_{11}-2 A_{12}+A_{22}\right) W_{1}^{2}+2\left(A_{12}-A_{22}\right) W_{1}+A_{22}},
$$

where $W_{1}-$ a molar fraction of one of the components. Coefficient $A_{i j}$ is determined by the anisotropic part of the polarizability of molecules of both components, $B_{i j}-$ by the size and sign of dipole-dipole and dipole-quadrupole interaction between molecules of different components and between molecules of one component. The pitch $P$ and $\theta$ is related by

$$
\frac{1}{P}=\frac{1}{2 \pi} \cdot\left(\frac{\mathrm{d} \theta}{\mathrm{d} y}\right)=\frac{1}{2 \pi} \cdot\left(\frac{\theta}{r}\right) .
$$

Since $r$ is unknown, then (7) and (8) allow the determination of the ratio between $A_{i j}$ and $B_{i j}$ only.

When one of components is nematic, then $B_{22}=B_{12}=0$ and

$$
\begin{aligned}
P^{-1}\left(W_{1}\right) & =\frac{1}{2 \pi r} \frac{\left(B_{11}-B_{21}\right) W_{1}^{2}+B_{21} W_{1}}{\left(A_{11}-2 A_{12}+A_{22}\right) W_{1}^{2}+2\left(A_{12}-A_{22}\right) W_{1}+A_{22}} \\
P^{-1}(1) & =\frac{1}{2 \pi r} \frac{B_{11}}{A_{11}} .
\end{aligned}
$$

From here

$$
\frac{P^{-1}(W)}{P^{-1}(1)}=\frac{\left(1-B_{21} / B_{11}\right) W_{1}^{2}+B_{21} / B_{11} W_{1}}{\left(1-2 A_{12} / A_{22}+A_{22} / A_{11}\right) W_{1}^{2}+2\left(A_{12} / A_{11}-A_{22} / A_{11}\right) W_{1}+A_{22} / A_{11}} .
$$

The authors calculated then coefficients for some mixtures with experimental fit of the reciprocal pitch versus concentrations.
Hanson, Dekker, Van der Woude [31] also used Goossens theory, however for the construction of curves they used a computer, while in [8] only few 
special points of each curve were employed and therefore $A_{i j} / B_{i j}$ differ for this cases.

In [28] the treatments $[8,31]$ were used for mixtures BMAOB with cholesteryl caprinate (CC). For the curve $1 / P$ versus $C$ at temperature $t_{\mathrm{c}}-4^{\circ} \mathrm{C}$ concentration range $55-95 \%$ of $\mathrm{CC}, P$ was not measured because values of $P$ lied in absorbed range of molecules, $A_{i j} / B_{i j}$ were calculated with the help of treatment $[8,31]$ and theoretical curve was calculated.

In the next work [34] Hanson, Dekker and Van der Woude reduced the number of coefficients up to 2 . $1 / P$ was written as a quadratic function of weight fraction $W$ one of the component

$\frac{1}{P}=W^{2} \frac{1}{P_{1}}+2 W(1-W) \frac{1}{P_{12}}+(1-W)$.

where $1 / P_{1}, 1 / P_{2}$ are reciprocal pitches of components, $1 / P_{12}$ - effective value of interaction of these components. This dependence confirmed empirical law obtained by Adams and Haas - formulae (3). For NCM :

$$
\frac{1}{P}=W^{2} P_{\text {chol }}+W(1-W) \frac{1}{P_{\text {chol nem }}} .
$$

In the paper data $\frac{1}{P_{\text {chol }}}+\frac{1}{P_{\text {chol nem }}}$ are listed for mixtures of nematic P-ethoxy benzylidene-p-n butylaniline (EBBA) and P-/P-ethoxy-benzilidene amino/ benzonitrile (PEBAB) with cholesteryl chloride (CCh). It was shown that $1 / P_{\text {chol nem }}$ is higher in the case EBBA-CCh. It is related to the fact that the buthyl band-group of EBBA is longer than that one of PEBAB.

De Gennes [8] has presented a treatment of the problem taking into account the long range distortions created in a nematic matrix by floating chiral molecules and received linear dependence between $1 / P$ and $C$;

$$
q_{0}=\frac{2 \pi}{P}=4 \pi \beta c
$$

where $q_{0}$ is a wave vector, $c$ is a number of solute molecules and $\beta$ is a constant (with the dimension of a surface), dependent on the nature of both solvent and solute, called microscopic twisting power of the solute (cholesteric).

Bak and Labes [35] by analogy with de Gennes, also used long range distortions induced by chiral molecules in nematic matrix. The resultant pitch in the multicomponent mixtures is found to be in general a quadratic function of number densities of component molecules. This quadratic pitch relation becomes a linear function of number densities only when the twisting power satisfy certain special conditions. For a two-component mixtures ( 1 and 2 ) the pitch is given by

$$
\frac{1}{P}=\frac{1}{n_{1}+n_{2}}\left[\beta_{1} n_{1}^{2}+2 \beta_{12} n_{1} n_{2}+\beta_{2} n_{2}^{2}\right]
$$

where $n_{1}\left(n_{2}\right)$ - number of 1 (2) molecules per $\mathrm{cm}^{3}$ in the mixture. $\beta_{1}-$ effective twisting power between 1 molecules, $\beta_{2}$ - between 1 and 2 , and $\beta_{2}$ - between 2 molecules accordingly. This relation is analogous to (3) and (10).

For nematic-cholesteric mixtures $\beta=0$ and

$$
\frac{1}{P}=\frac{2}{n_{1}+n_{2}}\left[\beta_{1} n_{1}^{2}+2 \beta_{12} n_{1} n_{2}\right] .
$$

For low concentrations of cholesteric component $n_{\mathrm{A}} \ll n_{\mathrm{B}}$ and

$$
\frac{1}{P}=4 \beta_{12} n_{1} .
$$

This relation is in agreement with experimental data for low cholesteric concentrations in NLC.

Then in terms of mole fraction of the cholesteric component $-m_{1}=\frac{n_{1}}{n_{1}+n_{2}}$ (14) has the form

$$
\frac{1}{P}=2 M m_{1}\left[\left(N \beta_{1}-2 N \beta_{12}\right) m_{1}+2 N \beta_{12}\right]
$$

where

$$
M=\left[\left(\frac{M_{1}}{\alpha_{1}}-\frac{M_{2}}{\alpha_{2}}\right) m_{1}+\frac{M_{2}}{\alpha_{2}}\right]
$$

molar density of the mixture, $M_{1}\left(M_{2}\right)$ - molecular weight of $1(2)$ component, $\alpha_{1}\left(\alpha_{2}\right)$ - density $\left(\mathrm{g} / \mathrm{cm}^{3}\right)$ of pure 1(2) component, $N$-Avogadro number.

The experimental data for the following compounds are used : MBBA + CCh, MBBA + cholesteryl-2(ethoxy-ethoxy)-ethyl carbonate (CEEC), P-/N-(Pmethoxybenzylidene) amino/-phenyl acetate (MBA) + cholesteryl propionate (CP), MBBA + cholesteryl oleyl carbonate (COC).

In conclusion the authors indicate that the parameter involved by Stegemeyer and Finkelmann (molecular polarizabilities) are not so readily accessible as the densities and they claim that their method has therefore some advantage.

Lisetski, Timan, Tischenko and Kolotij [36] extended the molecular statistical theory of Maier-Saupe on CLC, but unlike Goossens theory, they took into account steric repulsion forces. This approach includes more completely all the types of interaction between components of NCM.

Quite a different approach to this problem was made in work [26] where a theory based on molecular association was suggested. The authors refer to works $[22,37]$, in which Saeva and Wysocki have shown that the electronic transitions of molecules dissolved in the cholesteric mesophase become circularly dichroic, i.e. liquid crystal induced circular dichroism is observed, and the electronic interaction within the cholesteric helix depends on the helical pitch. Pochan and Hinnam suggested that a direct interaction between solute and solvent (somewhat analogous to the 
charge transfer complex) takes place. This interaction produces the shift on the wavelength of maximum selective reflection $\lambda_{\mathrm{m}}$ which occurs when chiral solutes are added to the nematic mesophase. Thus an equilibrium between cholesteric molecule (Ch) and nematic molecules $(\mathrm{N})$ is attained and a complex is formed

$$
\mathrm{Ch}+n \mathrm{~N} \rightleftarrows \mathrm{ChNn}
$$

Cholesteric and molecular complexes are assumed to have reflective pitches $\lambda_{\mathrm{Ch}}$ and $\lambda_{\mathrm{ChN}}$ respectively, while any unperturbed nematic molecules retain their infinite pitch : Equation for $\lambda_{\mathrm{m}}$ in mixtures is written

$$
\frac{1}{\lambda_{\mathrm{m}}}=\sum \frac{M_{i}}{\lambda_{i}}=\frac{M_{\mathrm{Ch}}}{\lambda_{\mathrm{Ch}}}+\frac{M_{\mathrm{ChN}}}{\lambda_{\mathrm{ChN}}}
$$

where $M_{i}$ is the mole fraction of individual components, $M_{\mathrm{Ch}}$ and $M_{\mathrm{ChN}}$ are functions of the complex number $n$. Then $\lambda_{\mathrm{m}}$ and $n$ are selected from experimental data.

The idea of intermolecular associate formation in NLC has been forwarded in [38], but the authors of this work consider the assumptions of Pochan and Hinman about the associate stoechiometry as nonadequate one. It is assumed instead that the associate composition is the same all over the concentration range. The dissociation processes are also taken into consideration. Because of short-range specific repulsions between the molecules of different kinds the associate has its specific characteristic intrinsic pitch values. The following association processes can take place :

$$
\mathrm{N}+\mathrm{Ch} \rightleftarrows \mathrm{NCh} ; \quad \mathrm{NCh}+\mathrm{Ch} \rightleftarrows \mathrm{NCh}_{2} .
$$

If we consider $\mathrm{N}_{m} \mathrm{Ch}_{n}$ associates (where $m=n=1$ or $m=1, n=2$ ) as one of the components of the systems, we may write

$$
P^{-1}=\sum P_{i}^{-1} W_{i}
$$

where $P_{i}^{-1}$ and $W_{i}$ are the helical twisting power and molar fraction of the $i$-th component, respectively. Considering that in the first approximation the equilibrium of associate formation reaction is completely shifted to the right in the point corresponding to stoichiometry of associate $\left(W=\frac{m}{m+n} \equiv W_{\text {ass }}\right)$, the concentration of associates is supposed to be equal to $100 \%$.

Accounting for dissociation (taking the degree of dissociation in the form of $(1-k))$ for $W_{\mathrm{N}}<W_{\text {ass }}$

$$
P^{-1}=K \frac{W_{\mathrm{N}}}{W_{\text {ass }}} P_{\text {ass }}^{-1}\left[1+\left(1+\frac{1-W_{\text {ass }}}{W_{\text {ass }}}\right)\right] P_{\mathrm{Ch}}^{-1}
$$

where $P_{\text {ass }}$ and $P_{\mathrm{Ch}}$-spiral pitch of cholesteric component and associate accordingly. For $W_{\mathrm{N}}>W_{\text {ass }}$

$$
P^{-1}=K \frac{1-W_{\mathrm{N}}}{W_{\mathrm{ass}}} P_{\mathrm{ass}}^{-1}+(1+K)\left(1-W_{\mathrm{N}}\right) P_{\mathrm{Ch}}^{-1}
$$

The equilibrium constant of the process with $W_{\mathrm{N}}<W_{\mathrm{NS}}$ has the form of

$$
\begin{aligned}
K_{\text {ass }}=K W_{\mathrm{N}} & {\left[(1-K) W_{\mathrm{N}}\right]^{-m} \times } \\
\times & {\left[1-\left(1+\frac{1-W_{\text {ass }}}{W_{\text {ass }}}\right) W_{\mathrm{N}}\right]^{-n} . }
\end{aligned}
$$

As it was shown by the authors, the theoretical model curves thus obtained are quite well consistent with the experimental data.

\section{Temperature dependence of the helical pitch of} NCM. - One of the most important features of cholesteric systems is the temperature dependence of helical pitch. Changes of helical pitch (or colour) are the base for a wide practical application of CLC. On the other hand, using electrooptic effects, we usually want the threshold voltages to be independent of temperature [39]. These threshold voltages in turn depend on helical pitch. Almost all the cholesterol esters exhibit $\mathrm{d} P / \mathrm{d} t$ value which is negative. Goossens [33] in his theory has shown that either $\mathrm{d} P / \mathrm{d} t=0$ or the pitch may only slightly increase with temperature near the clearing point.

Keating [40] proposed the dynamic theory, which explained negative $\mathrm{d} P / \mathrm{d} t$ values for cholesterics. This is based on the presence of anharmonicity in the forces resulting the relative twist of neighbouring planes of molecules and it views the macroscopic twist as the rotational: analogous of thermal expansion Böttcher [41] modified the Keating's theory. He also took into account the damping of rotation of molecules in viscous medium. From Keating-Böttcher's theory one can obtain a linear dependence of $1 / P$ from $T$. $\frac{1}{P}=b_{1}+b_{2} T \cdot b_{1}$ and $b_{2}$ are choosen empirically.

One can observe all three types of dependence of $P$ on $T$ in nematic-cholesteric mixtures. For instance, in BMAOB + cholesteryl caprinate (CC) mixtures up to 12 weigh $\%$ of $\mathrm{CC} \mathrm{d} P / \mathrm{d} t>0$ when concentration of $\mathrm{CC}$ is in $12-40 \%$ interval $\mathrm{d} P / \mathrm{d} t=0$ and when concentration of $\mathrm{CC}$ is more than $40 \% \mathrm{~d} P / \mathrm{d} t<0$ [28]. The temperature dependence of helical pitch for EBBA + cholesteryl chlorid (CCh) mixtures is considered in the paper [42].

Many authors tried to explain the dependence of $P$ on $T$ theoretically. But the models proposed in $[43,44]$ have not provided a description of the influence of structure of mesogenic molecules on the character of $P(\mathrm{~T})$ curves. For example a molecular model proposed in the paper [43] which takes into account non-dispersion forces, stipulating for anharmonicity 
in rotational oscillations of molecules is considered only in general without any analysis of intermolecular interaction in concrete systems.

In the paper [45] a model was proposed in which molecular field, hindering the rotational vibration of molecules weakens with the lowering of the orientational order parameter $\eta$. $\eta$ to a first approximation is determined from Maier-Saupe's theory. For the average twist angle $\theta_{\mathrm{P}}$ one obtains $\theta_{\mathrm{P}}=\theta_{0}+u_{\mathrm{v}} \frac{t}{\eta(t)}$ where $\theta_{0}$ is a twist angle corresponding to the minimum of the interaction energy $t=0.22 \frac{T}{T_{\mathrm{is}}}\left(T_{\mathrm{is}}\right.$ is clearing point) and $u_{\mathrm{v}}$ are forces stipulating anharmonicity in rotational vibrations. These forces are caused by steric repulsion of separate parts of mesogenic molecules.

In the papers $[46,47]$ attempts were made to evaluate $\mathrm{d} P / \mathrm{d} t$ quantitatively. Finkelmann and Stegemeyer have shown that hindered long-axis rotation around the long molecular axis causes the helical pitch to increase with temperature increase. But theoretically predicted value of the relative temperature gradient of reciprocal pitch $\left(\approx 0.3 \%\right.$ per $\left.{ }^{\circ} \mathrm{C}\right)$ is approximately twice as low as typical experimental results. In the paper [47] $\mathrm{d} P / \mathrm{d} t>0$ is connected with an increased random scattering of molecular long axes around the director. The authors have shown that average twist angle values decrease with the deterioration of orientational order. This leads to the relative temperature gradient of pitch of about $0.4 \%$ per ${ }^{\circ} \mathrm{C}$ (degree).

At the VII International Liquid Crystal Conference there were some reports [48-51] devoted to the temperature dependence of pitch.

Goossens used both dipole-dipole and dipolequadrupole interactions to extend the molecular-statistical theory of Maier and Saupe in order to explain the helical structure however with a temperature independent pitch. In the report [48] Goossens has shown that local biaxiality on a molecular scale may be important and thus influences the temperature dependence of the pitch. But the value of parameters introduced by the authors is not determined yet. Therefore, it is difficult to predict the character of temperature dependence from this theory.

Kimura, Hoshino and Nakano [49] investigated theoretically an orientational ordering in cholesteric liquid crystals by assuming the intermolecular force being the sum of a repulsion of hard core with shape of twisted rod (modificated model of Straley [52]) and dispersion forces of Maier-Saupe type and of Goossens type. By this model they explained temperature dependence both for cholesterics and chiral nematics.

Van der Meer and Vertogen [50] have shown that the interaction which induces the twist in the system, finds its origin both in the anisotropy of the Van der Waals forces and in the repulsive forces arising from the specific shape of the molecules. Authors also studied the influence of presmectic fluctuations on temperature dependence of pitch.

Schröder [51] considered the molecular statistical theory with the help of the Luckhurst's model [53]. In this case one gets $\mathrm{d} P / \mathrm{d} t<0$.

Listeski starts from the idea of $[43,44]$ to combine the approaches of Goossens and Keating in a general form of intermolecular potential. However, the authors of the idea tried to solve the problem in an over-generalized form, which made their expressions so complicated that they became virtually of no practical use. One evidently has to make some simplifications without losing the adequacy of the model. Lisetski introduced a general expression for the angular dependence of intermolecular potential, bearing in mind two interacting molecules in adjacent quasinematic layers

$$
V(\theta)=-\eta\left\{\imath P_{2}\left[\cos \left(\theta-\theta_{0}\right)\right]+\sum_{r} u_{r} R_{r}(\theta)\right\}
$$

where $P_{2}$ is the Legendre polynomial, $\eta$ is Maier-Saupe orientational order parameter; its values as it was shown in [54, 55] are practically the same in both nematics and cholesterics, and the Maier-Saupe function is considered to be quite a good approximation to $\eta(T)$ dependences in cholesteric systems. The symmetry-breaking terms expressed by $R(\theta)$ functions are considered to arise from a slight inadequacy of the Goossens's theory multipole expansions do not account for geometric peculiarities of molecular structure usually referred to as steric factors. The averaged twist angle values are derived from the expression

$$
\bar{\theta}_{P}=\frac{2 \pi}{P}=\frac{\int_{-\pi / 2}^{\pi / 2} \theta_{\exp }[-V(\theta) K T \mathrm{~d} \theta]}{\int_{-\pi / 2}^{\pi / 2} \exp [-V(\theta) K T \mathrm{~d} \theta]}
$$

Now, if we put $R(\theta)=\sin ^{3}\left(\theta-\theta_{0}\right)$ and use the Maier-Saupe reduced temperature $t=\frac{K T}{V}=0.22 T / T_{\mathrm{i}}$ ( $T_{\mathrm{i}}-$ is isotropic transition point), model $P(t)$ curves are readily obtained with only two parameters involved : $\theta$ and $U_{o}=U / 3 v$.

The first one expresses the Goossens' chirality and the second is a measure of steric factors responsible for the rotational vibration unharmonicity.

An analytical solution for the case $U_{v} \gtrsim \theta_{0}$ was obtained and proved to provide a quantitative description for cholesteric derivatives and their mixtures $[45,56]$. Another analytical solution was presented in [47] for the case $\theta_{0} \gg U_{v}$ i.e. for negligible anharmonicities. That seems to be the case for $\mathrm{NLC}+\mathrm{OAD}$ systems with $\mathrm{d} P / \mathrm{d} t>0$.

Introduction of the rotational order parameter $S_{\mathrm{R}}(T)=\left\langle 1-2 \sin ^{2} \psi\right\rangle[46,57]$ brings in no qualitative changes. Relative values acquire a small positive addition, but the decisive role in determining of its 
sign remains with the relative values of $\theta_{0}$ and $U_{v}$. Absolute $P$ values, however, may depend upon $S_{\mathrm{R}}$ greatly, as it has already been shown [57].

Another kind of symmetry - breaking forces is represented by angle-dependent steric repulsions between the molecules of different species in nematiccholesteric mixtures. If we approximate $R(\theta)$ by a step function in a narrow range of the angles of mutual orientation

$$
R(\theta)= \begin{cases}1 & \theta_{\mathrm{r}}-O<\theta<\theta_{\mathrm{r}}+O \\ 0 & \text { for the other } \theta \text { values }\end{cases}
$$

Lisetski obtains correct magnitudes of extra twisting power values [36]. The source of these peculiar forces in presumably found in the so-called angular methyl groups stretching an above-situated nematic molecule from taking orientations inside $\Delta \theta_{\mathrm{r}} \equiv 2 i$.

This quite non-trivial behaviour has been observed experimentally in EBBA-CC systems [58]. As for nematic-cholesteric mixtures where the cholesteric component forms left-handed helix by itself the theory predicts a sign inversion of $\mathrm{d} P / \mathrm{d} t$, i.e. one has to expect $P$ increasing with temperature when $\mathrm{CC}$ concentration is low, $\mathrm{d} P / \mathrm{d} t$ becoming negative with higher values.

Analysing theoretical models of Lisetski and experimental data one can go to the following conclusions. Let us consider at first the case when in NCM NLC is non-smectogenic. If cholesterol esters are used as optically active dopant, one has to consider two extreme cases :

1) When the concentration of cholesterics $(C)$ is too small. There is no source of steric hindrance in this case. The character of $P(T)$ dependence is determined by average twist angle values decreasing with the deterioration of orientational order of molecular long axes. Therefore $\mathrm{d} P / \mathrm{d} t>0$. The same result one obtains, if we use CC and CCh (smectogenic) [28, 42] as well as cholesteryl formate (nonsmectogenic) figure 2 [59].

2) When concentration of cholesterics is large enough, the source of sterical hindrances appears. The rotational vibrations non-harmonicity increases with increasing temperature ; this leads to $\mathrm{d} P / \mathrm{d} t<0$. This theoretical prediction is confirmed experimentally in $[28,59]$.

When non-mesomorphic substances or chiral nematics (CN) served as optically active dopants, the first case takes place, if the concentration of OAD is small. $(\mathrm{d} P / \mathrm{d} t=0$ or $\mathrm{d} P / \mathrm{d} t>0$.) See, for instance, the report [39]. Authors of [36] have got the same results for L-menthol derivatives (Fig. 3).

If we use OAD structure which serves as a strong source of rotational vibration non-harmonicity, we can obtain $\mathrm{d} P / \mathrm{d} t<0$ even for small concentrations of OAD because with these substances this property may be marked more than with cholesterol derivatives. One observed this feature with 1-DDCO [11] and also with tygogenyn and its derivatives (Fig. 4).

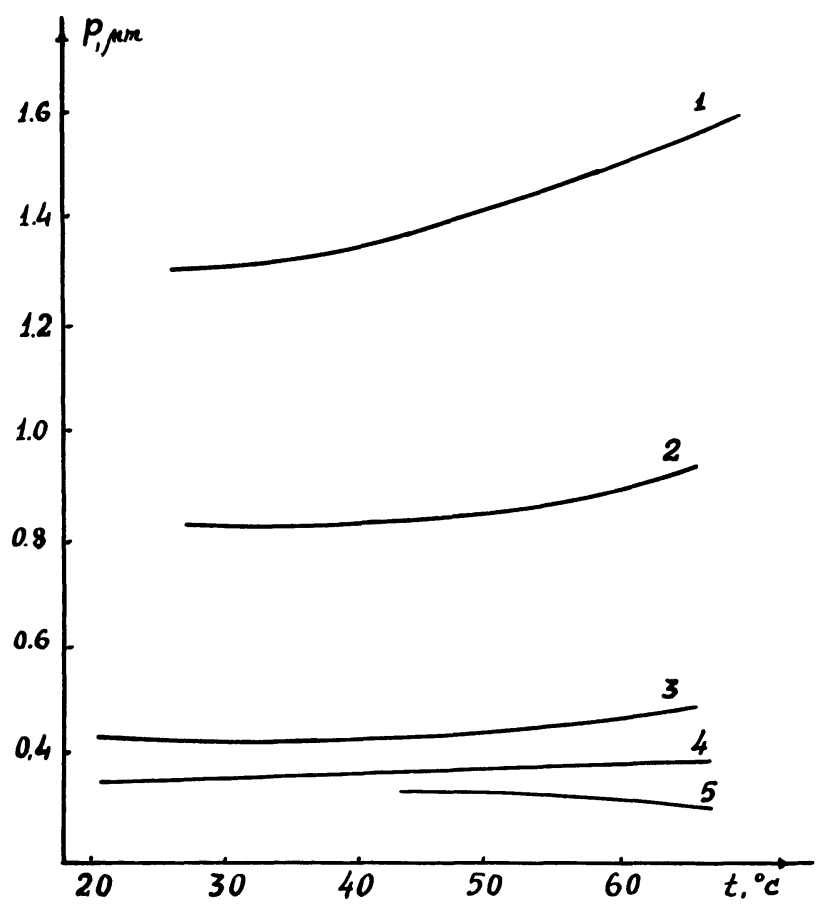

Fig. 2. - Temperature dependence of the pitch for mixtures BMAOB + CF. $1-5 \%$ of CF $; 2-10 \%, 3-20 \%, 4-27,5 \%, 5-80 \%[59]$.

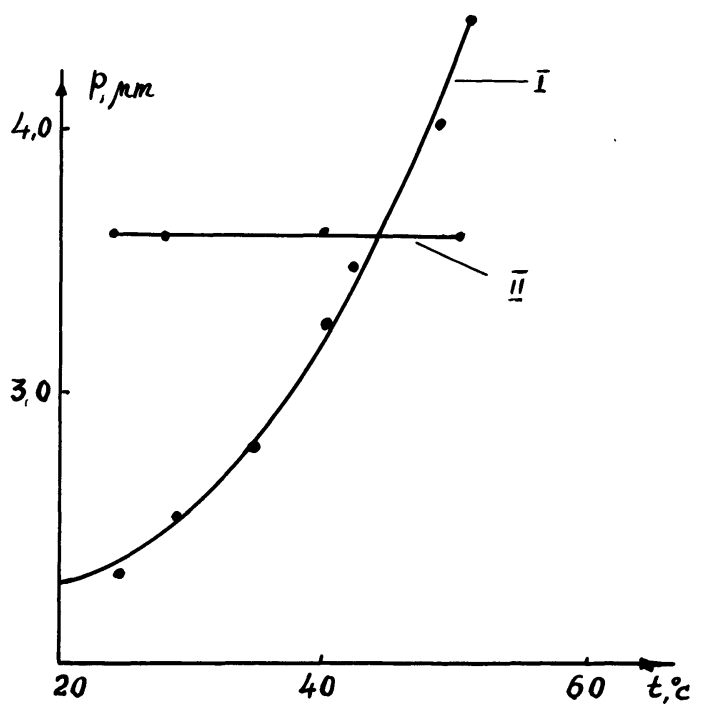

Fig. 3. - Temperature dependence of the pitch for mixtures : I) $95 \%$ BMAOB $+5 \%$ L-menthyl oxalate. II) $95 \%$ BMAOB $+5 \%$ menthyl chloroacetate.

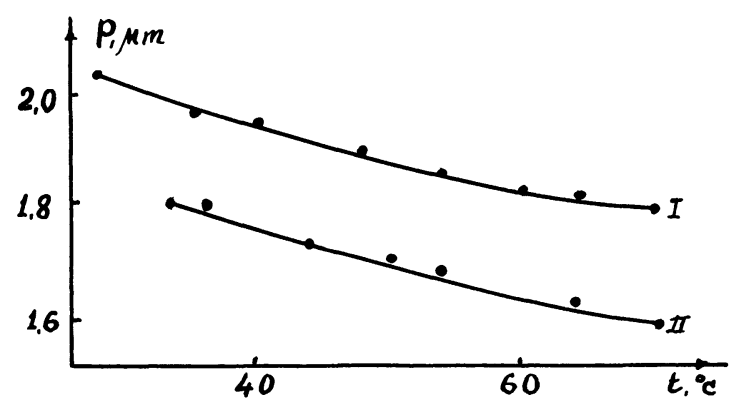

Fig. 4. - Temperature dependence of the pitch for mixtures I) $97 \%$ BMAOB $+3 \%$ Tygogenin acetate. II) $97 \%$ BMAOB - $3 \%$ Tygogenin 
It has been shown that when introducing small quantities of OAD into a smectogenic NLC matrix a typical picture of pretransitional phenomena is obtained with $P \rightarrow \infty$ near the translational phase transition, as in cholesterol esters forming smectic - A mesophase. The large increase in $P$ when $T$ is decreased for the most of cholesterics is due to the onset of a short range order of the smectic type [60-63].

In [64] the following substances were used as NLC s : 4-nitrophenyl-4'-octyloxybenzoate (NPOOB) and 4-cyano 4'-octyloxybiphenyl (COOB), both forming the smectic-A mesophase, 4-nonyloxybenzoic acid (NOBA) forming the smectic-C mesophase, and also, for comparison, 4-buthoxybenzoic acid (BOBA), being purely nematogenic and forming no smectic mesophase at all. The cholesteryl formate (non-smectogenic) and caprinate (smectogenic) introduced in small quantities ( $\leqslant 40 \%$ ) were used as OAD s.

As we can see from figure 5, both smectogenic and non-smectogenic cholesterol esters acting as optically active dopants in smectogenic nematic matrices produce $P(T)$ dependences very similar to those of purely cholesteric systems with pretransitional phenomena. The negative temperature dependence of pitch was observed up to a visible light range.

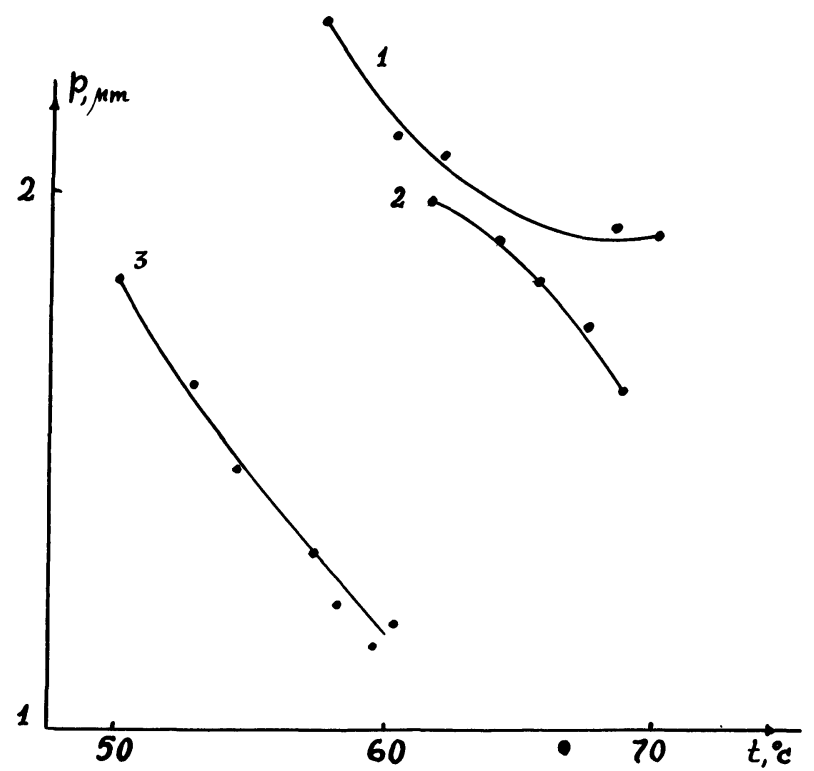

Fig. 5. - Temperature dependence of the pitch for mixtures : 1) $93 \% \mathrm{COOB}+7 \% \mathrm{CF}$; 2) $93 \% \mathrm{NPOOB}+7 \% \mathrm{CC} ; 3)$ $95 \%$ NPOOB $+5 \%$ CP [64].

The unwinding of cholesteric helix occurs regardless of the nematic component ability to form smectic - A or smectic - C mesophase (see Fig. 6).

But if we use non-smectogenic nematics, such as BOBA, the character of $P(T)$ dependence changes drastically, with $\mathrm{d} P / \mathrm{d} t$ becoming positive (see Fig. 7). Hence, the temperature dependence of pitch in nematic-cholesteric mixtures depends on the presence of smectic order in nematic matrix.

It seems now clear that induced cholesteric mesophases can show the most varied types of thermo-

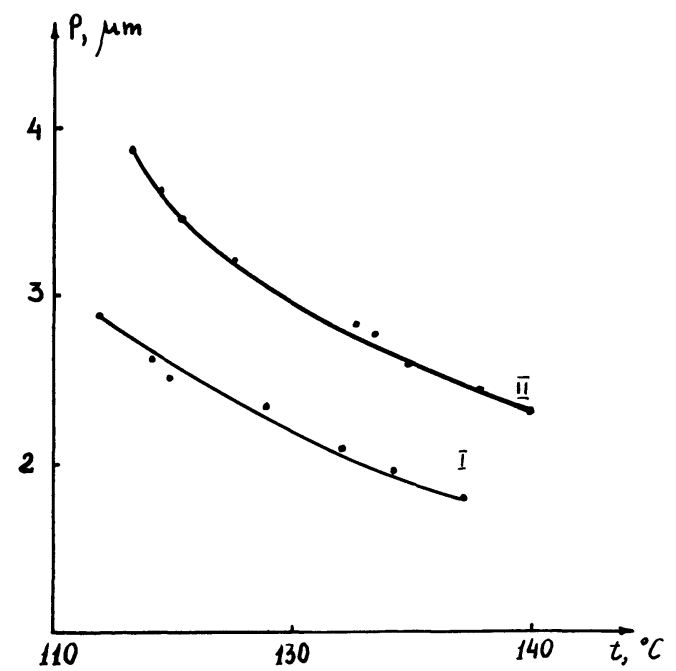

Fig. 6. - Temperature dependence of the pitch for mixtures : 1) $97 \% \mathrm{NOBA}+3 \% \mathrm{CC}$; 2) $97 \%$ NOBA $+3 \% \mathrm{CF}$ [64]

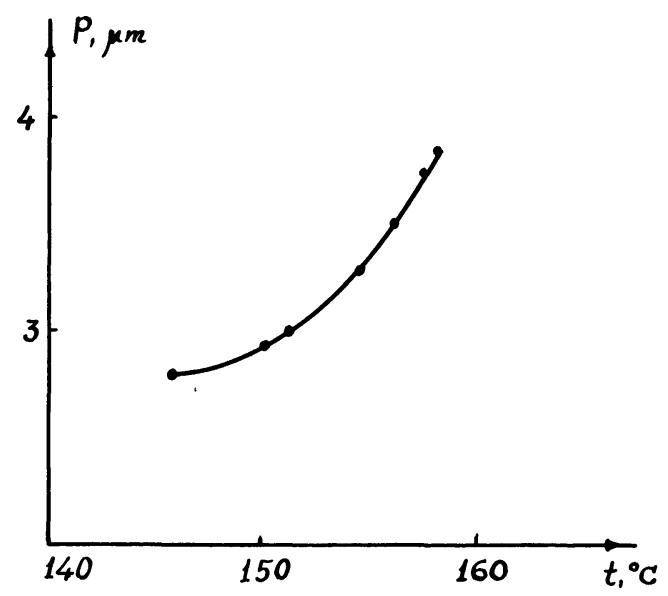

Fig. 7. - Temperature dependence of the pitch for $95 \%$ BOBA $+5 \%$ CF [64].

chromic behaviour which enables them to complete successfully with the traditional mixtures of cholesterol derivatives.

4. Chiral nematic liquid crystals. - As we have already pointed out in the Introduction here is another class of organical compounds, possessing helical structure. Molecules of these substances are chiral and contain an assymmetric centre. These optically active substances were called chiral nematic (CN) liquid crystals (LC). The racemic mixtures of these $\mathrm{LC}$ have nematic structure. One ought to point out that racemic mixtures of cholesterol derivatives also form a nematic structure, but molecules of $\mathrm{CN}$ have nematogenic (extended) form unlike the steroidal form of molecules of CLC. This structural similarity to nematics defines the difference in viscosity, birefringence and other physical parameters of $\mathrm{CN}$ from these of CLC. All the classes of NLC with the optically active radical have already been synthesized. Let us begin from $\mathrm{CN}$ with Schiff's bases. 
As it is pointed out in the works $[1,2,65]$ Friedel described amil-p-1,4-cyano-benzilidencinnamat in 1922 :<smiles>CC[C@H](C)COC(=O)C=Cc1ccc(N=Cc2ccc(C#N)cc2)cc1</smiles>

In order to observe cholesteric-to nematic transition Heilmeier and Goldmacher [66] used the mixture of this CN with NLC with $\Delta \varepsilon>0$.

Cano and Chatelain $[67,68]$ investigated mixtures of active and nonactive forms of this compound.

Castellano [65] suggested to use the following series of combinations with low phase temperature and low threshold voltage of cholesteric to nematic transition :<smiles>CC[C@H](C)CCOc1ccc(C=Nc2ccc(C#N)cc2)cc1</smiles>

In [69] the viscosity (under flow) of the following chiral nematic was studied :<smiles>CCC(C)CC(=O)C=Cc1ccc(N=Cc2ccc(OC)cc2)cc1</smiles>

It has been shown that viscosity of this $\mathrm{CN}$ is much smaller than the one of cholesterol esters.

The series of $\mathrm{CN}$ was described in [70] :

(R)-4-n-alcoxybenzilyden-4'(2-methylbhutyl) anilin<smiles>[R20]c1ccc(/C=N/c2ccc(C[C@@H](C)CC)cc2)cc1</smiles>

(R)-4-n-alcoxybenzylyden-4'(3-methylpentyl) anilin<smiles>[R20]c1ccc(/C=N/c2ccc(CCC(C)CC)cc2)cc1</smiles>

(R)-4-n-alcoxybenzylyden-4'(4-methylhexyl) anilin<smiles>[R20]c1ccc(C=Nc2ccc(CCC[C@H](C)CC)cc2)cc1</smiles>

The methoxy, ethoxy and buthoxy members of benzal$\mathrm{p}(\beta$-methylbutyl) anilin series in both their active and racemic forms were studied in report [25]. They have a low temperature phase NLC and CN. Their thermo- dynamic properties, the indices of refraction and pitch of helix were investigated.

In works $[71,72]$ the following substances were described :<smiles>CC[C@H](C)CC(=O)Oc1ccc(/N=C/c2ccc(O[14CH3])cc2)cc1</smiles>

In the patent [71] it has been pointed out that the mixture of racemic LC of this series $(n=1)$ with MBBA and EBBA (concentration $1: 1: 1$ ) formed the $\mathrm{LC}$ wide phase range from $-40^{\circ} \mathrm{C}$ up to $65^{\circ} \mathrm{C}$. The dynamic scattering on this mixture has better time characteristics as compared with other nematics and their mixtures. The mixture containing an optically active component also has better time of dynamic 
scattering with storage in comparison with cholesterol esters. In the [72] the substances with $n=1 \div 5$ were investigated, when $n=1$, the pitch of helix is stable with temperature, and when $n=3$ or $n=5 \mathrm{~d} P / \mathrm{d} t<\mathrm{LO}$ (Fig. 8). In the paper [73] the racemic and active forms for $n=1$ have been investigated. The temperature dependence of the refractive indices and dielectric constants for both structures are measured.
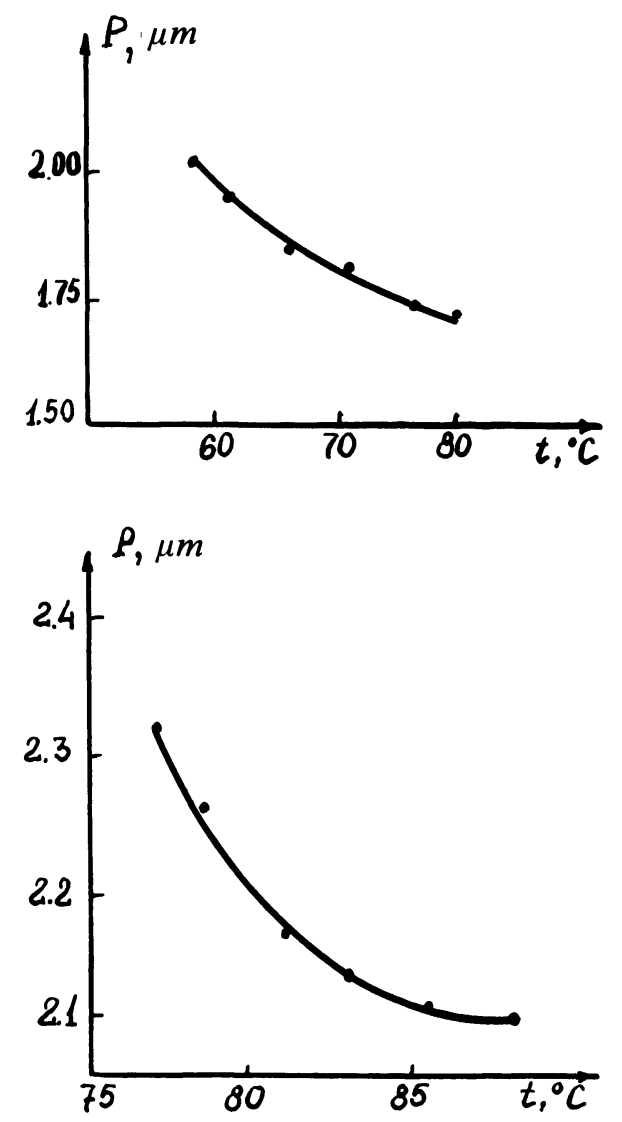

Fig. 8. - Temperature dependence of the pitch for $\mathrm{CN} \mathrm{n}^{\circ} 3$ and $\mathrm{CN}$ n $^{\circ} 5$.

The arranged layer of NLC with $\mathbf{L}$ as the predominant direction is in fact an uniaxial crystal with positive optical anisotropy $n_{\mathrm{e}}>n_{0}$ (where $n_{\mathrm{e}} \equiv n_{\| \mathrm{L}}$ is the refraction index for an extraordinary beam and $n_{0} \equiv n_{\perp \mathrm{L}}$ is the refraction index for an ordinary beam).

The chiral (cholesteric) structure is a special case of a nematic structure when the predominant direction $\mathbf{L}$ describes a helix, the optical anisotropy in CLC being negative : $n_{0 h}>n_{\text {eh }}$ (where $n_{\mathrm{ch}} \equiv n_{\| \mathbf{h}}$ and $n_{0 h} \equiv n_{\perp \mathrm{h}}$ are the refraction indices for the extraordinary and the ordinary beams respectively, and index $h$ is the direction of the axis of the helix). Indicating the refraction indices of a nematic CLC monolayer through $n_{\mathrm{c}}^{\prime}$ and $n_{0}^{\prime}$ we shall, proceeding from the geometry of the CLC structure, obtain :

$$
n_{\mathrm{e} h}=n_{0}^{\prime} \quad n_{\mathrm{oh}}=\sqrt{\frac{n_{\mathrm{e}}^{\prime 2}+n_{0}^{\prime 2}}{2}} .
$$

The optical anisotropy of the LC phase is determined by the polarizability anisotropy of the molecules of the substance and degree of their order parameter $(S)$. Comparison of the obtained data enables to assume that the orientational order parameter $S$ in the nematic monolayer of the cholesteric liquid crystal is the same as that in the nematic liquid crystal (Fig. 9). The same results for another materials have been obtained by Pelzl [74].

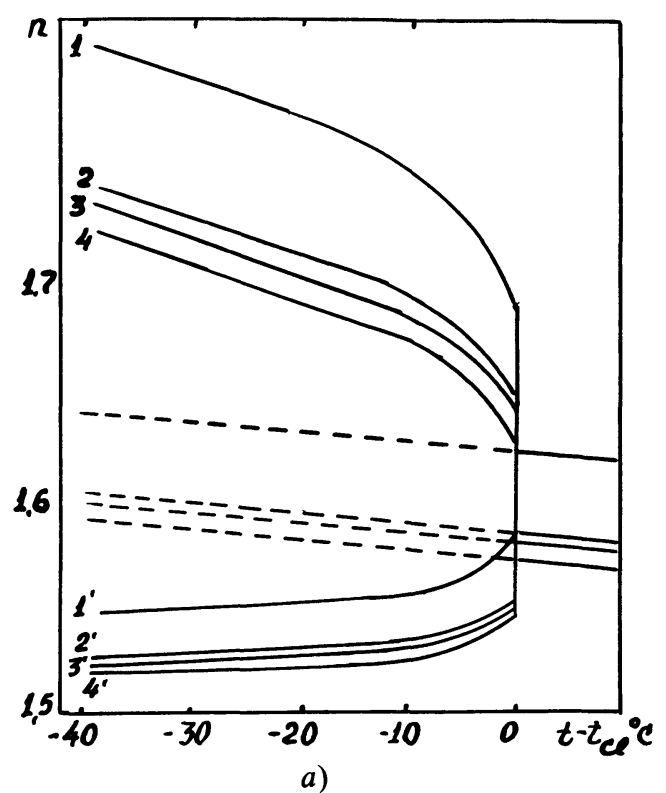

Fig. 9a. - Indices of refraction of NLC : 1) $n_{\mathrm{e}}$ and $1^{\prime}-n_{0}$ for $436 \mathrm{~nm}$; 2) $n_{\mathrm{e}}$ and $2^{\prime}-n_{0}$ for $546 \mathrm{~nm}$; 3) $n_{\mathrm{e}}$ and $3^{\prime}-n_{0}$ for $577 \mathrm{~nm}$; 4) $n_{\mathrm{e}}$ and $4^{\prime}-n_{0}$ for $690 \mathrm{~nm}$.

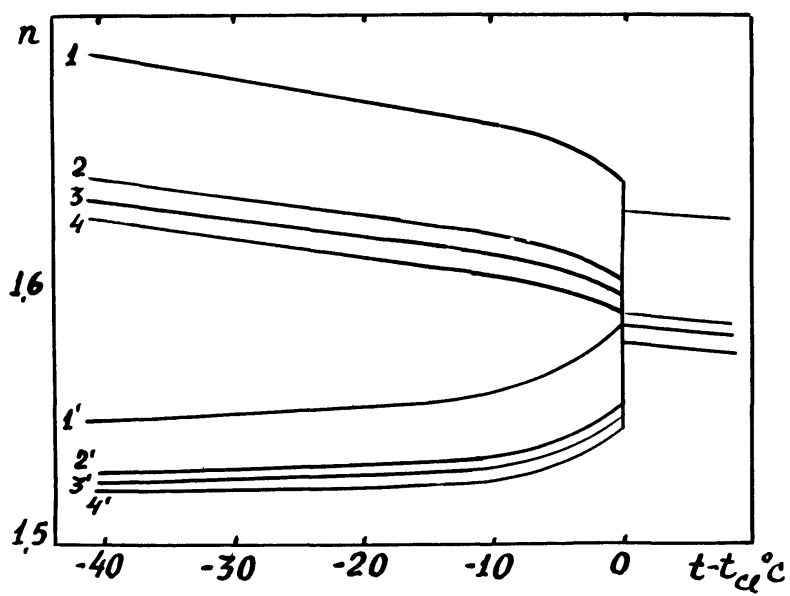

b)

Fig. $9 b$. - Indices of refraction of CNLC :1) $n_{0 h}$ and $1^{\prime}-n_{\mathrm{eh}}$ for $436 \mathrm{~nm}$; 2) $n_{0 h}$ and $2^{\prime}-n_{\text {eh }}$ for $546 \mathrm{~nm}$; 3) $n_{0 h}$ and $3^{\prime}-n_{\text {eh }}$ for $577 \mathrm{~nm}$; 4) $n_{0 h}$ and $4^{\prime}-n_{\text {eh }}$ for $690 \mathrm{~nm}$ [73]. 
In [75] mixtures of azo and azoxy compound with asymmetric side chain, e.g.

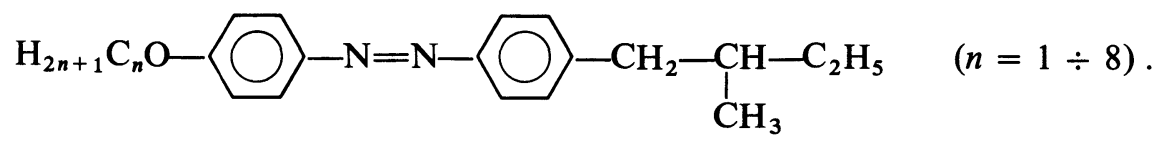

were studied and a nematic liquid crystal, their pitch and sense of the helix were examined. Compounds with two identical optically active side chains exhibited the twisting power twice that of compounds with one optically active side chain.

In [76] chiral nematic esters were studied. Two types of these esters are shown below

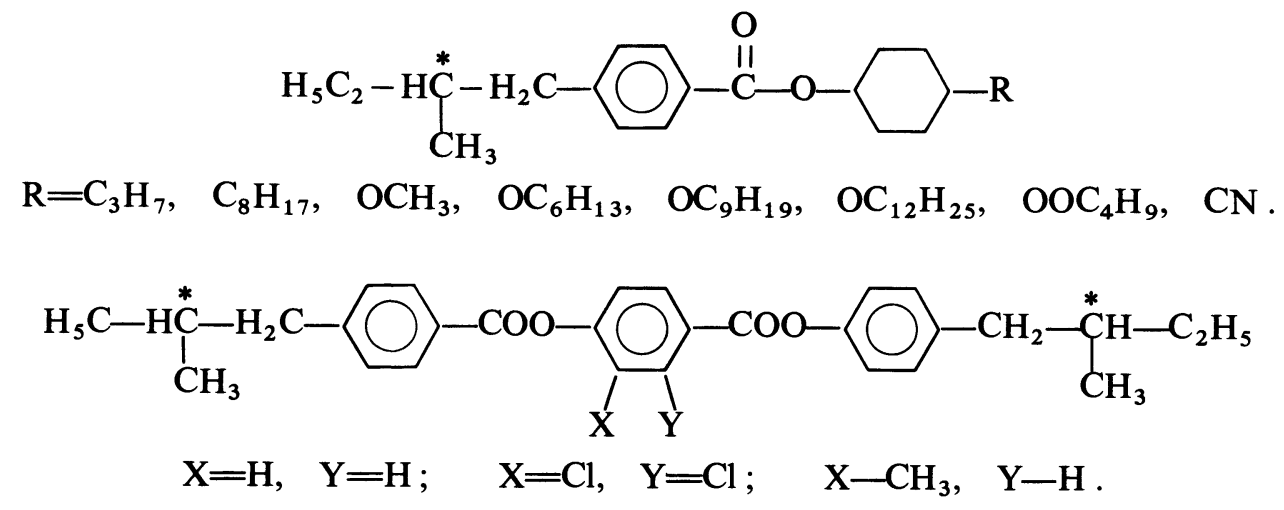

These liquid crystal materials are right-handed, have very small optical pitch and high chemical stability.

In [77] a homologous series of P-(2-methyl-bytoxyphenyl-P'-alxoxybenzoates of a general formula

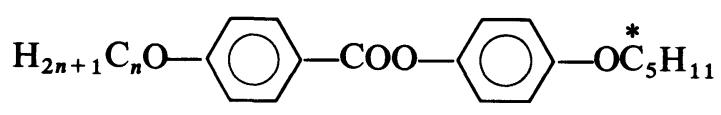

has been prepared. $\mathrm{CN}$ phase observed for $n=7$.

A number of chiral nematic, incorporating the biphenyl ring system, have been prepared and studied by Gray and McDonnall [78-81]. In [80] authors have formulated a simple rule relating molecular structure, absolute configuration and twist sense. The rule is that, if the absolute configuration of the chiral centre is $\mathrm{S}$, then the helix sense of the chiral nematic is lefthanded $(\mathrm{L})$ if the chiral centre is at an odd number $(\mathrm{O})$ of atoms from the ring system, and right-handed (D) if the number of atoms is even (E). The opposite applies when the chiral centre is of $\mathrm{R}$ configuration. Thus the possible combinations are SOL ; SED, ROD, REL only.

So at present a wide range of chiral nematics has been synthesized with appropriate melting points, clearing temperatures, pitch values and viscosities good in display devices application.

\section{References}

[1] Gray, G. W., Molecular Structure and Properties of Liquid Crystals (Academic Press, New York) 1962.

[2] Chistyakov, Y. G., Liquid Crystals (Nauka Publ. Moscow) 1966, in Russ.

[3] De Gennes, P. G., The Physics of Liquid Crystals (Clarendon Press, Oxford) 1974.

[4] Kapustin, A. P., Experimental Investigations of Liquid Crystals (Nauka Publ. Moscow) 1977, in Russ.

[5] BuInov, L. M., The Electro and Magneto-Optics of Liquid Crystals (Nauka Publ., Moscow) 1978, in Russ.

[6] Chistyakov, Y. G., Kristallografiya 7 (1962) 764.

[7] Buckengham, A. D., Ceasar, G. P., Dunn, M. B., Chem. Phys. Lett. 3 (1969) 540.

[8] Finkelmann, H., Stegemeyer, H., Ber. Bunsenges Phys. Chem. 78 (1975) 869.

[9] Stegemeyer, H., Mainusch, K. J., Chem. Phys. Lett. 6 (1970) 5.

[10] Stegemeyer, H., Mainusch, K. J., Steigner, H., Chem. Phys. Lett.' , (1971) 425.
[11] Stegemeyer, H., MainusCh, K. J., Naturwiss. 58 (1971) 599.

[12] Stegemeyer, H., Mainusch, K. J., Chem. Phys. Lett. 16 (1972) 38.

[13] Park, J. W., Labes, M. M., MCLC 31 (1975).

[14] Berthault, J. P., Billard, J., Jacques, J., C. R. Hebd. Séan. Acad. Sci. 284c (1977) 155.

[15] Berthault, J. P., Dissertation, Collège de France, Paris, France.

[16] Ruxer, J. M., Solladie, G., Candau, S., Mol. Cryst. Liq. Cryst. 41 (1978) 109.

[17] Elashvili, Z. M., Piliashvili, T. S., Chilaya, G. S., II Int. Conf. on LC's of SOC. countries - Slanchev Bryag (Sept. 27-30), 1977), F-2; Z. Chem. 19 (1979) 453.

[18] Topchiashvili, E. E., Elashvili, Z. M., Chilaya, G. S., Museridze, M. D., Dzotsenidze, Z. G., Bull. Acad. Sci. Georgian SSR 83 (1976) 101 (in Russian).

[19] Elashvili, Z. M., Mkhatvrishvili, M. D., Piliashvili, T. S., Chilaya, G. S., Japaridze, K. G., J. Physique Colloq. 40 (1979) C3-22. 
[20] Heppke, G., Oestreicher, F., Z. Naturforsch. 32a (1977) 899. [21] Aronishidze, S. N., Brodzeli, M. I., Mkhatvrishvili, M. D. Tevdorashvili, K. G., Chilaya, G. S. Liquid Crystals and Practical applications (Proc. of Ivanovo State Univ.) 1976, p. 57, in Russ.

[22] Saeva, F. D., Wysocki, J. J., J. Am. Chem. Soc. 93 (1971) 5928.

[23] Nakagiri, T., Kodama, H., Kobayashi, K. K., Phys. Rev. Lett. 27 (1971) 564.

[24] Cano, R., Chatelain, P., C. R. Hebd. Séan. Acad. Sci. 253 (1961) 1815 .

[25] Dolphin, P., Mulgiani, Z., Cheng, J., Meyer, R. B., J. Chem. Phys. 58 (1973) 413.

[26] Pochan, J. M., Hinman, D. P., J. Phys. Chem. 78 (1974) 1206.

[27] Nakagiri, T., Phys. Lett. 36A (1971) 427.

[28] Chilaya, G. S., Aronishidze, S. N., Vinokur, K. D., MkhatVRishVili, M. D., KRISTAllografiYa 22 (1977) 1280.

[29] Kozawaguchi, H., Wada, M., Japan. J. Appl. Phys. 14 (1975) 651 .

[30] Finkelmann, H., Stegemeyer, H., Z. Naturforsch 28a (1973) 799.

[31] Hanson, H., Dekker, A. J., Van der Woude, F., J. Chem. Phys. 62 (1975) 1941.

[32] Adams, J., HaAs, W., Mol. Cryst. Liq. Cryst. 30 (1975) 1.

[33] Goossens, W. Y. A., Phys. Lett. 31A (1976) 413.

[34] Hanson, H., DekKer, A. J., VAn DeR Woude, F., Mol. Cryst. Liq. Cryst. 42 (1977) 15.

[35] BaK, C. S., Labes, M. M., J. Chem. Phys. 62 (1975) 3066.

[36] Lisetski, L. N., Timan, B. L., Tishenko, V. G., Kolotil, O. D., Ukr. Fiz. Zhurnal 23 (1978) 94.

[37] Saeva, F. D., Mol. Cryst. Liq. Cryst. 18 (1972) 375.

[38] Kudryashova, T. P., Lisetski, L. N., Chistyakov, Y. G., Zhurn. Fiz. Khim. 12 (1978) 2194.

[39] Heppke, G., Oestreicher, F., 7 Liquid Crystals Conf. Bordeaux (1978) Abstracts, DP 31

[40] Keating, P. N., Mol. Cryst. Liq. Cryst. 8 (1969) 315.

[41] BotTCHer, B., Chem. Z-tg. 96 (1972) 214.

[42] Hanson, H., Dekker, A. J., Van Der Woude, F., Mol. Cryst. Liq. Cryst. 42 (1977) 15.

[43] Lin-Liu, Y. R., Shin, Y. M., Woo, C. W., Tan, H. T., Phys. Rev. A 14 (1976) 445 ; A 15 (1977) 2550.

[44] Van der Meer, B. W., Vertogen, G., Dekker, A. J., Y PMA, J. G., J. Chem. Phys. 65 (1976) 3935.

[45] Lisetski, L. N., Tolmachev, A. V., Tischenko, V. C., Pis'ma ZHETF 27 (1978) 205.

[46] Stegemeyer, H., Finkelman, H., Naturwiss. 62 (1975) 436.

[47] Lisetski, L. N., Timan, B. L., Tischenko, V. C., Koloti, O. D., Fizika Tverdogo Tela 19 (1977) 3461

[48] Goossens, W. J. A., VII Int. Conf. IC, Bordeaux) (1978) Abstracts, CP 25.

[49] Kumura, H., Hoshino, M., NaKano, H., ibid., CP 29.

[50] VAN Der Meer, B. W., Vertogen, G., ibid., CP 48.

[51] SCHRODER, H., ibid., EP 40.
[52] Straley, J. P., Phys. Rev. 14 (1976) 1835.

[53] Luckharst, G. R., Zannoni, C., Nordi, P. L., Segre, O. U., Mol. Phys. 30 (1975) 1345

[54] Tolmachev, A. V., Tischenko, V. G., Lisetski, L. N., Fiz. Tverd. Tela 19 (1977) 1886.

[55] Collings, P. J., McColl, J. R., Solid State Commun 28 (1978) 997.

[56] Kudryashova, T. P., Lisetski, L. N., Chistyakov, G., Kristallografia 24 (1979) 998.

[57] Finkellmann, H., Stegemeyer, H., Ber. Bunsenges Phys. Chem., 82 (1978) 1302.

[58] Sato, S., Wada, M., J. Jpn. Soc. Appl. Phys. Suppl. 42 (1973) 276.

[59] Lisetski, L. N., Chilaya, G. S., Vinokur, K. D., Tischenko, V. G., Panikarskaya, V. D., Ukr. Fiz. Zhurnal 24 (1979) 1082.

60] De Gennes, P. G., Solid State Commun. 10 (1972) 753

[61] Alben, P., Mol. Cryst. Liq. Cryst. 20 (1973) 231.

[62] Sonin, A. S., Tolmachev, A. V., Tischenko, V. G., BaK, V. G., Zh. Eksp. Teor. Fiz. 68 (1975) 1951.

[63] Pindak, R., Huang, C., J. Ho. Phys. Rev. Lett. 32 (1974) 43.

[64] Vinokur, K. D., Ivchenko, S. P., Chilaya, G. S., Zh. Tekh. Fiz. 49 (1979) 1565.

[65] Castellano, J. A., RCA. Rev. 33 (1972) 296.

[66] Heilmeier, G. H., Goldmacher, J. E., J. Chem. Phys. 51 (1969) 1258

[67] Cano, R., Chatelain, P., C. R. Hebd. Séan. Acad. Sci. 253 (1961) 1815

[68] Cano, R., Chatelain, P., C. R. Hebd. Séan. Acad. Sci. 259 (1964) 352.

[69] Friedman, E. M., Porter, R. S., MCLC 31 (1975) 47.

[70] HsU, Y. Y., DolPhIN, D., MCLC 42 (1977) 327.

[71] Castellano, J. A., McCaffrey, M. T., Patent 20936 87, 1972.

[72] Elashvili, Z. M., Chilaya, G. S., Aronishidze, S. M., Brodzeli, M. I., JAPARIDZe, K. G., Bull. Acad. Sci. Georgian SSR 81 (1976) 105. In Russian.

[73] Chilaya, G. S., Aronishidze, S. N., Elashvili, Z. M., KushNIRENKo, M. N., BRODZELI, M. I., ibid. 84 (1976) 81.

[74] Pelzl, G., Z. Chem. 17 (1976) 264.

[75] Tsukamoto, M., Ohtsuka, T., Morito, K., Muzakami, Y., Jap. J. Appl. Phys. 14 (1970) 1307.

[76] Klanderman, B. B., Criswell, T. R., J. Am. Chem. Soc. 97 (1975) 1585.

[77] Loseva, M. N., Chernova, N. I., Doroshina, N. I., III Liquid Crystals Conference of Socialist Countries (1979) G. 2, Abstracts.

[78] Gray, G. W., McDonnall, D. G., MCLC 37 (1976) 189

[79] Gray, G. W., McDonnall, D. G., Electronics Lett. 11 (1975) 556.

[80] Gray, G. W., McDonnall, D. G., MCLC 34 (1977) 217.

[81] Gray, G. W., Advances in LC Materials for Applications BDH Chem. Ltd. (1978). 